\title{
Comparison between five coprological methods for the diagnosis of Balantidium coli cysts in fecal samples from pigs
}

\author{
Juan Carlos Pinilla1 ${ }^{10}$, Andrea Isabel Pinilla² and Angel Alberto Florez ${ }^{1}$ (D) \\ 1. Department of Veterinary Medicine, Faculty of Exact, Natural and Agricultural Sciences, University of Santander, \\ Bucaramanga, Colombia; 2. Department of Microbiology, Faculty of Health, Industrial University of Santander, \\ Bucaramanga, Colombia. \\ Corresponding author: Juan Carlos Pinilla, e-mail: jcpinilla65@gmail.com \\ Co-authors: AIP: andreaisabpinilla@gmail.com, AAF: ang.florez@mail.udes.edu.co \\ Received: 24-07-2020, Accepted: 23-02-2021, Published online: 12-04-2021
}

doi: www.doi.org/10.14202/vetworld.2021.873-877 How to cite this article: Pinilla JC, Pinilla AI, Florez AA (2021) Comparison between five coprological methods for the diagnosis of Balantidium coli cysts in fecal samples from pigs, Veterinary World, 14(4): 873-877.

\begin{abstract}
Background and Aim: Balantidium coli is a protozoan that can infect humans and non-human primates, being the domestic pigs the animals most affected by this parasite. This study aimed to compare the performance of five coprological methods for diagnosis of Balantidium coli cysts in fecal samples from pigs.

Materials and Methods: From September to December 2019, 558 fecal samples were collected from the rectum of backyard pigs in the Bucaramanga metropolitan area, Colombia. The average age of the sampled animals was 3-4 months. Fecal samples collected were tested using the following coprological techniques: Direct examination with Lugol's iodine solution, buffered saline, centrifugation/flotation and McMaster techniques, and Ziehl-Neelsen method.

Results: The results indicate that B. coli cysts were diagnosed most frequently through direct examination with Lugol's iodine solution $(52.7 \%$ of the samples) followed by direct examination with a buffered saline solution (37.6\%). Moderate concordance $(\mathrm{k}=0.41 ; \mathrm{p}<0.05)$ was determined between direct method with Lugol's iodine and buffered saline solution, McMaster and buffered saline $(\mathrm{k}=0.35 ; \mathrm{p}<0.05)$, and centrifugation/flotation and buffered saline $(\mathrm{k}=0.28 ; \mathrm{p}<0.05)$ showed a fair degree of concordance. The rest of the comparisons were classified as poor. The flotation techniques (centrifugation/ flotation and McMaster) did not show good recovery of cysts.
\end{abstract}

Conclusion: It is concluded that the most efficient method for diagnosing this parasitosis was to an association between direct examination with Lugol's iodine solution and buffered saline.

Keywords: Balantidium, parasite, pigs, protozoan.

\section{Introduction}

Balantidium coli is a ciliated protozoan that can infect humans and non-human primates; however, domestic pigs are the animals most affected by this parasite. This protozoan has a cosmopolitan distribution with prevalence ranges in pigs between 33\% and 94\% [1]. In humans, balantidiosis can manifest clinically as asymptomatic hosts that can serve as reservoirs of infection to patients with severe balantidiosis passing mucoid, bloody stools [2,3]. This parasitic disease is acquired by humans through the fecal-oral route from the pig which is the normal asymptomatic host [4]. This protozoan has two evolutionary forms: Trophozoite and the cyst. The trophozoite can measure up to $120 \mu \mathrm{m}$ in width by $150 \mu \mathrm{m}$ in length, while the cyst, which may be spherical, measures 40-60 $\mu \mathrm{m}$ in diameter [4].

The diagnosis of $B$. coli is based on the observation of evolutionary forms in feces, by light optical

Copyright: Pinilla, et al. Open Access. This article is distributed under the terms of the Creative Commons Attribution 4.0 International License (http://creativecommons.org/licenses/by/4.0/), which permits unrestricted use, distribution, and reproduction in any medium, provided you give appropriate credit to the original author(s) and the source, provide a link to the Creative Commons license, and indicate if changes were made. The Creative Commons Public Domain Dedication waiver (http://creativecommons.org/ publicdomain/zero/1.0/) applies to the data made available in this article, unless otherwise stated. microscopy [4]. Due to its large size and spiral motility, B. coli trophozoite can be easily recognized on wet slide preparations; the cyst, by its spherical form is also easily recognizable [4].

Several authors have reported the use of different coprological techniques for the diagnosis of $B$. coli. Nishi et al. [5] used flotation methods with glucose for the diagnosis of protozoan in pigs. Weng et al. [6] used direct methods and flotation solution with sodium chloride for the diagnosis. On the other hand, Sanchez [7] using direct examination for diagnosing B. coli in human stool samples, and Barbosa et al. [8] compared five coprological techniques for the diagnosis of B. coli cysts in fecal samples from pigs and non-human primates. Azevedo et al. [9] used four parasitological techniques to study intestinal parasites in fecal samples from people from Brazil.

The clinical diagnosis of intestinal parasitic infections is inaccurate because it is based on non-specific clinical manifestations. Therefore, laboratory diagnosis plays an important role in the diagnosis of these infections [10]. Despite the existence of numerous quantitative and qualitative techniques for parasitological examination of feces, there is very little information about studies that have evaluated the performance of diagnostic methods to identify B. coli 
cysts [8]. A reference technique with a high percentage of precision and security is not generally available for parasitological studies, especially to detecting gastrointestinal parasites [11].

Therefore, it is important to review coprological diagnostic methods to determine more accurate results for the diagnosis of this parasitosis. Accordingly, the aim of this study was to compare five coprological techniques for laboratory diagnosis of $B$. coli cysts in fecal samples from pigs.

\section{Materials and Methods}

Ethical approval

This research was approved by the Institutional Ethical Committee of the University of Santander (ref No CIF0311-19).

\section{Study site and period}

The research was conducted in farms located in the Bucaramanga metropolitan area $\left(7^{\circ} 08^{\prime} 00^{\prime \prime} \mathrm{N} 73^{\circ} 08^{\prime} 00^{\prime \prime} \mathrm{W}\right)$, department of Santander, Colombia [12]. This region comprises a geographical area of $1479 \mathrm{~km}^{2}$. Rainfall is regular throughout the year; however, more rains are experienced from October to December. Bioclimatic characteristics of the region are similar and with the mean annual temperature of $25^{\circ} \mathrm{C}$, with little weather varies throughout the year. Altitude is between 600 and 1700 masl and the mean annual rainfall is $1040 \mathrm{~mm}$, with $78 \%$ relative humidity [12]. The study was conducted from September to December 2019.

\section{Study design}

A cross-sectional and descriptive study was designed. Sixty-four backyard pig farms were visited, and fecal samples were collected weekly. Most of the pigs sampled were crossbreeds between Yorkshire, Landrace, and Pietrain. The average age of the sampled animals was 3-4 months. The expected sample size was determined using the formula provided by Thrusfield [13]. As the prevalence of B. coli in the local pig population was unknown, the hypothesized prevalence of $75 \%$, with a confidence level of $95 \%$, an estimated sample size of 558 fecal samples was determined to compare the five coprological diagnostic methods. Eight to nine fecal samples were randomly collected from each farm examined. A sample was considered positive if at least it showed one protozoan cyst.

\section{Sample collection and laboratory analysis}

Fecal samples were collected from the rectum of pigs using palpation gloves. Approximately $10 \mathrm{~g}$ of feces without chemical preservative were obtained from each animal. Samples were placed into containers filled with ice packs and immediately transported to the laboratory for processing. Part of the fecal sample was processed by direct methods with Lugol's iodine solution (1:5 dilutions) and buffered saline [14], and the rest of the sample was processed by the other coprological techniques. For the McMaster technique,
$2 \mathrm{~g}$ of feces were mixed with $28 \mathrm{~mL}$ of the sugar-salt flotation solution $(1 \mathrm{~L}$ of saturated $\mathrm{NaCl}$ plus $500 \mathrm{~g}$ of sugar, at room temperature $\left(27^{\circ} \mathrm{C}\right)$ and $1.32 \mathrm{~g} / \mathrm{mL}$ specific gravity) [15], in a $50 \mathrm{~mL}$ Falcon tube, and vigorously agitated until complete homogenization and left undisturbed. After 6-8 min, a $0.5 \mathrm{~mL}$ sample of the supernatant was taken and placed in the McMaster chamber for reading. B. coli cysts were counted, and the total number of cysts was multiplied by a coefficient of 50 [16]. However, a sample was considered positive if at least one cyst was observed in the chambers. The centrifugation/flotation technique (Sheater technique) included 2-3 $\mathrm{g}$ of feces that were suspended in tap water and sieved (mesh size: $250 \mu \mathrm{m}$ ) into a $100 \mathrm{~mL}$ glass beaker. After 3 min of sedimentation, the supernatant was discarded, and the sediment was transferred to a $10 \mathrm{~mL}$ tube and centrifuged $(400 \mathrm{~g} \times$ $5 \mathrm{~min}$ ). The supernatant was discarded again, and the sediment was resuspended in a tube with sugar-salt solution up to a formation of the convex meniscus. After 10 min of flotation, the meniscus was lifted with a microscopical slide and examined microscopically to $100 \times$ [17]. For the Ziehl-Neelsen method, a thin layer of feces was transferred to the center of the slide and spread the material with a cotton swab. Air-dried at room temperature $\left(27^{\circ} \mathrm{C}\right)$, fixed with methanol for $5 \mathrm{~min}$ and colored with carbol fuchsin for $4 \mathrm{~min}$, and rinse until the water runs clear. Then, wash and decolorized with the hydrochloric acid-ethanol and rinse until the water is clear. Cover the slide with methylene blue for 1 min, wash with tap water and dry. The slide was observed microscopically with immersion oil at $40 \times$ and $100 \times$. The cyst structure, if present, is seen in purple red on a blue background [14].

\section{Statistical analysis}

The results of this study were analyzed by the Chi-square test to determine statistical differences, with confidence intervals of $95 \%$. The kappa index $(\mathrm{k})$ was calculated to determine the concordance among the five coprological technics, and this kappa index was interpreted according to the classification indicated by Barbosa et al. [8]. The level of significance for the analyses was 5\%. Calculations were made using the SPSS Statistics for Windows (IBM, USA), version 21.0 [18].

\section{Results}

B. coli cysts were detected in $79.2 \%$ of the fecal samples, by at least one coprological technique. Table-1 shows the comparison (Chi-square test) between recovery rates of $B$. coli cysts among the five coprological techniques used. Different recovery percentages were observed, suggesting a statistical association $(\mathrm{p}<0.05)$ with respect to the technique. B. coli cysts were observed most frequently using the direct method with Lugol's iodine solution (52.7\%), followed by the direct examination with a buffered saline solution $(37.6 \%)$, centrifugation/flotation technique 
Table-1: Recovery rate of $B$. coli cysts by the coprological techniques used $(n=558)$.

\begin{tabular}{lcccc}
\hline Technique & Positives & Negatives & \% & p-value \\
\hline $\begin{array}{l}\text { Lugol's iodine } \\
\text { solution }\end{array}$ & 294 & 264 & 52.7 & 0.000 \\
$\begin{array}{l}\text { Buffered saline } \\
\text { solution }\end{array}$ & 210 & 348 & 37.6 & \\
$\begin{array}{l}\text { Centrifugation/ } \\
\text { flotation }\end{array}$ & 166 & 392 & 29.7 & \\
$\begin{array}{l}\text { McMaster } \\
\text { Ziehl-Neelsen }\end{array}$ & 106 & 452 & 19 & \\
\hline
\end{tabular}

Statistically significant $(p<0.05)$. B. coli=Balantidium coli

(29.7\%), and McMaster technique (19\%). The ZiehlNeelsen method showed poor performance in detecting $B$. coli cysts $(0.35 \%)$.

Regarding the kappa index, the highest values were observed in the comparison between direct examination with Lugol's iodine and buffered saline solution $(\mathrm{p}<0.05)$, showing a moderate concordance between both methods $(\mathrm{k}=0.41 ; \mathrm{p}<0.05)$. On the other hand, the comparisons between McMaster and buffered saline $(\mathrm{k}=0.35 ; \mathrm{p}<0.05)$ and centrifugation/flotation and buffered saline $(\mathrm{k}=0.28 ; \mathrm{p}<0.05)$ showed a fair degree of concordance. The rest of the comparisons were classified as poor, and the kappa index was not statistically significant ( $>0.05)$ (Table-2).

\section{Discussion}

B. coli is a protozoan with a zoonotic potential worldwide. Most infections by this pathogen in pigs are subclinical and usually limited to the small intestine. In some cases, after injures of the intestinal wall by other agents as bacteria and virus, the trophozoites can penetrate the mucosa causing diarrhea, bloody feces, and even death of the pig. Therefore, the diagnosis of this protozoan must be opportune [19]. In this research, the use of the five coprological methods allowed detecting $B$. coli cysts, in the fecal samples from pigs. However, other studies on the examination of $B$. coli have reported using at least two coprological methods $[5,6]$. Overall, direct examination with Lugol's iodine solution presented the highest recovery rate of detection of $B$. coli oocysts followed by examination direct with a buffered saline solution. Probably, $B$. coli cysts tend to be found more on the superficial layer of the fecal sample, since the material from digested food goes for a few movements, therefore hindering the spread of parasitic structures. Therefore, fecal scraping may have favored the observation of the protozoan as indicated by Barbosa et al. [8]. According to Figueroa-Castillo et al. [14], Lugol's iodine is a rapid, non-specific contrast dye that is added to direct wet mounts of fecal material to aid in differentiating parasitic cysts from other non-parasitic structures. In this sense, many protozoa as $B$. coli cysts (Figure-1a) absorb the dye and appear brown while other objects in the sample remain clear. On the other hand, the buffered solution did not stain the
Table-2: Concordance of the results obtained through coprological techniques applied to $B$. coli cysts $(n=558)$.

\begin{tabular}{lcc}
\hline Technique & $\mathbf{k}$ & p-value \\
\hline Lugol $\times$ BS & 0.41 & 0.000 \\
MM $\times$ BS & 0.35 & 0.005 \\
CF $\times$ BS & 0.28 & 0.000 \\
MM $\times$ CF & 0.03 & 0.5 \\
BS $\times$ ZN & -0.1 & 0.34 \\
Lugol $\times$ ZN & -0.02 & 0.5 \\
CF $\times$ ZN & -0.02 & 0.58 \\
MM $\times$ ZN & -0.03 & 0.49 \\
Lugol $\times$ CF & -0.05 & 0.9 \\
Lugol $\times$ MM & -0.005 & 0.23 \\
\hline B. COII
\end{tabular}

B. coli=Balantidium coli, $\mathrm{k}=$ Kappa index, $\mathrm{CF}=$ Centrifugation/flotation, $\mathrm{MM}=$ McMaster, $\mathrm{ZN}=$ Ziehl-Neelsen, BS=Buffered saline. Statistically significant $(p<0.05)$

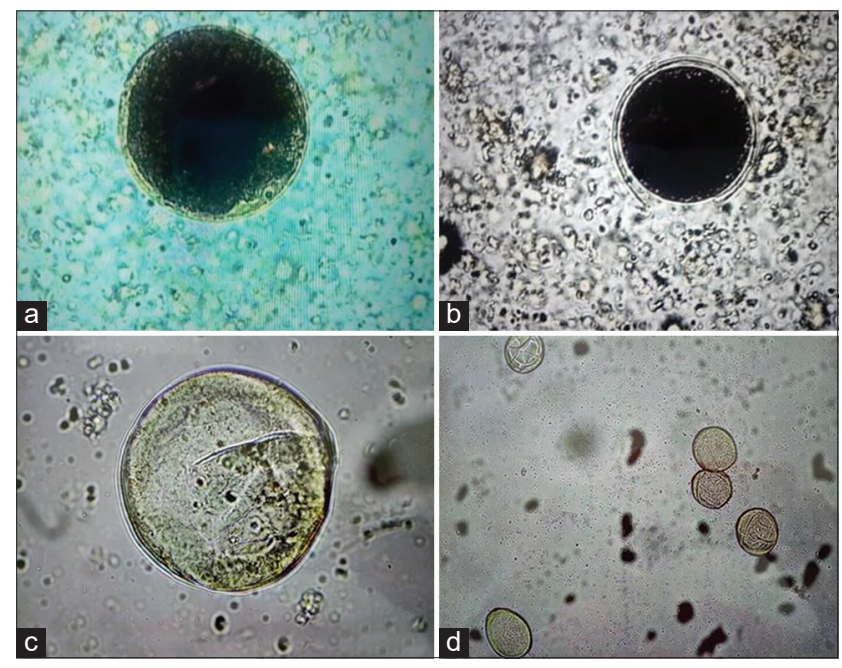

Figure-1: Cysts of Balantidium coli observed in fecal samples from pigs by different coprological techniques: (a): Lugol's iodine solution, (b): Buffered saline solution, (c): Centrifugation/flotation technic, (d): McMaster technic.

cysts, which often made it difficult to observe them (Figure-1b) in the light microscope. The direct methods have many advantages, especially its methodological facility, short runtime, and low cost; therefore, it should be recommended in the parasitological routine for the recovering of protozoan cysts and trophozoite in fecal samples without chemical preservatives [20]. According to Dryden et al. [21], flotation methods are the most widely used in veterinary parasitology. These technics are frequently used to recover lightweight parasitic such as protozoan cysts and oocysts [21]. However, in our study, the lowest values of cysts recovery were determined employing the centrifugation/flotation (29.7\%) and McMaster (19\%) methods. Although in these two methods, the sugar-salt solution makes it difficult for fecal detritus to float, which facilitates the viewing of parasite structures [22], in this study, B. coli cysts tended to become wrinkled through losing liquid to the more concentrated medium (Figure-1c and d), even if the microscope slide was read immediately after laboratory analysis. This alteration was detected in the present study, thus 
indicating that the sugar-salt solution used in flotation methods generally causes deformities in $B$. coli cysts. Therefore, these technics showed lower performance for the diagnosis because it gave rise to morphological changes to the cysts, causing often it difficult to recognize them. This morphological alteration detected had already been indicated by Dryden et al. [21], as a problem. According to these authors, sugar solutions could compromise the integrity of protozoan cysts, being a problem in diagnosing of these endoparasites. On the other hand, the McMaster technique is a coprological method that utilizes fecal samples to determine the fecal egg count, moreover, permitting the detection of parasitic elements as helminth eggs, protozoan oocysts, and cysts [23,24]. This technique is widely used by veterinarians and plays a crucial role in monitoring parasite charges in herds and in epidemiological studies [25]. However, in our study, this technique showed low efficiency in the diagnosis because this technique could be affected by a low amount of stool (2 g), higher multiplication factor (50), and the absence of centrifugation. According to Roepstorff and Nansen [24] and Vadlejch et al. [25], this technique improves the sensitivity when enough amount of fecal material (4 g), a low multiplication factor (20), and centrifugation steps are selected. We think that with the lack of centrifugation, the fecal suspension was not sufficiently clear for the examination of $B$. coli cysts. In our study, we have used the Ziehl-Neelsen technique to visualize Cryptosporidium oocysts; however, we have also used this technique to find $B$. coli cysts, without good results. A rounded structure of $60 \mu$ in diameter with no stain red color was found in all microscopic slides examined. We think that due to its morphological characteristics, it is $B$. coli cyst. This coprological technique is used for the diagnosis of resistant alcohol-acid bacteria like Mycobacterium and some intestinal coccidia such as Cryptosporidium, Cyclospora, Sarcocystis, and Isospora [14]. These infectious agents have fatty acids in their cell walls that give them the property of resisting decolorization with acid alcohol after using phenolic fuchsin (red color). Therefore, the structure is stained red, allowing its visualization [14]. Probably, the absence of cell wall in $B$. coli cysts does not allow the cyst to stain red when reacting with carbol fuchsine.

When comparing the results obtained by the five coprological methods, not all the kappa index values were statistically significant. In this sense, it was determined that the highest kappa values were observed between direct examination with Lugol's iodine solution and buffered saline, that is, the methods that showed the highest frequency of positivity. Therefore, these results indicate that the degree of agreement between both methods was moderate by the kappa index. Although this concordance was moderate $(\mathrm{k}=0.41)$, it is demonstrated that not all the positive samples were recovered using either technique. Therefore, to increase the performance of detecting
B. coli cysts, the results of this study show that there is a need to combine both direct methods. The different performance observed in the recovery of $B$. coli cysts from fecal samples from pigs could be associated with the consistency of the sample and the parasitic infection intensity. Moreover, the amount of fecal material examined and the sugar-salt solution used in the coprological analysis [26].

\section{Conclusion}

It is concluded that $B$. coli cysts were more frequently observed by direct examination with Lugol's iodine solution, and the most efficient method for diagnosing this parasitosis was to an association between direct examination with Lugol's iodine solution and buffered saline. In this study, the flotation methods were not shown good recovery rates for $B$. coli cysts and therefore are not suitable for investigating this protozoon.

\section{Authors' Contributions}

JCP conceived and designed the research. JCP and AAF conducted the sample collection. JCP and AIP processed samples in the Laboratory of Veterinary Clinical Research. JCP and AAF carried out the data analysis and writing of the manuscript. All the authors read and approved the submitted version of the manuscript.

\section{Acknowledgments}

The authors thank the staff of the Clinic Research Laboratory of the Veterinary Program of University of Santander, Colombia, for their help in the analysis of the samples. The authors thank the University of Santander, Colombia, for financial support of this project No. CIF 0311-19.

\section{Competing Interests}

The authors declare that they have no competing interests.

\section{Publisher's Note}

Veterinary World remains neutral with regard to jurisdictional claims in published institutional affiliation.

\section{References}

1. de Guzman, R., Nessi, A., González, H., Hernández, M., Galindo, M., Dorta, A., Wagner, C., Vethencourt, M. and de Pérez, G. (2013) Balantidium spp in Pigs and their Breeders: Prevalence in Communities of two States of Venezuela. VITAE Academia Biomédica Digital, No. 54. Available from: http://www.bioline.org.br/titles? $\mathrm{id}=\mathrm{va} \& y e a r=2013 \&$ $\mathrm{vol}=0 \&$ num $=54 \&$ keys $=$ V0N54. Retrieved on 15-04-2020.

2. Vásquez, W. and Vidal, J. (1999) Balantidiasic colitis: About a fatal case in the department of Huancavelica. An. Fac. Med., 60(2): 119-123.

3. Yazar, S., Altuntas, F., Sahin, I. and Atambay, M. (2004) Dysentery caused by Balantidium coli in a patient with non-Hodgkin's lymphoma from Turkey. World. J. Gastroenterol., 10(3): 458-459.

4. Schuster, F. and Ramirez-Avila, L. (2008) Current world 
status of Balantidium coli. Clin. Microbiol. Rev., 21(4): 626-638.

5. Nishi, S.M., Gennari, S.M., Lisboa, M.N., Silvestrim, A., Caproni, L. and Umehara, O. (2000) Intestinal parasites in pigs confined in the states of São Paulo and Minas Gerais. Arq. Inst. Biol., 67(2): 199-203.

6. Weng, Y., Hu, Y., Li, Y., Li, B., Lin, R., Xie, D., Gasserc, R. and Zhua, X. (2005) Survey of intestinal parasites in pigs from intensive farms in Guangdong Province, People's Republic of China. Vet. Parasitol., 127(3-4): 333-336.

7. Sanchez, K.E. (2013) Identification of Balantidium coli in People Dedicated to Pig Farming in the Canton Rafts during September 2012 to February 2013. Thesis. National University of Loja, Ecuador. Available from: http://www. dspace.unl.edu.ec/jspui/handle/123456789/4034. Retrieved on 18-07-2020.

8. Barbosa, S., Bastos, O.M., Uchôa, C.M., Pissinatti, A., Pereira, A.C., de Souza, I., Verdan, L., Peixoto, E., de Siquiera, M., Lessa, M. and Reis, M.R. (2016) Comparison of five parasitological techniques for laboratory diagnosis of Balantidium coli cysts. Rev. Bras. Parasitol. Vet., 25(3): 286-292.

9. Azevedo, E.P., Almeida, E.M., Matos, J.S., Ramos, A.R., Siquiera, M.P., Fonseca, A.B., Barbosa, A.S., Bastos, O.M. and Uchôa, C.M. (2017) Parasitological diagnosis in faecal samples in the clinical analysis laboratory: Comparison of techniques and cost of implantation. Rev. Bras. An. Clin., 49(4): 401-407.

10. Machado, E.R., Santos, D.S. and Costa-Cruz, J.M. (2008) Enteroparasites and commensals among children in four peripheral districts of Uberlândia, State of Minas Gerais. Rev. Soc. Bras. Med. Trop., 41(6): 581-585.

11. Gonçalves, A., Abellana, R., Silva, H., Santos, I., Serra, P., Julião, G., Puccinelli, P. and Ascaso, C. (2014) Comparison of the performance of two spontaneous sedimentation techniques for the diagnosis of human intestinal parasites in the absence of a gold standard. Acta. Trop., 131: 63-70.

12. Gobernación de Santander. (2017) Municipios del Departamento de Santander. Available from: http://www. santander.gov.co/d/index.php/es/mainmeneldpto/mendepmun2017. Retrieved on 15-03-2020.

13. Thrusfield, M. (2007) Veterinary Epidemiology. $3^{\text {rd }}$ ed. Blackwell Science Ltd., Oxford. p624.

14. Figueroa-Castillo, J.A., Jasso-Villazul, C., LiébanoHernández, E., Martínez-Labat, P., Rodríguez-Vivas, R.I. and Zárate-Ramos, J.J. (2015) In: Rodríguez-Vivas, R.I., editors. Coproparasitoscopic Examination: Techniques for the Diagnosis of Parasites with Importance in Public and Veterinary Health. Ampave-Conasa, México, DF.
15. Henriksen, S.A. and Christensen, J.P. (1992) Demonstration of Isospora suis oocysts in faecal samples. Vet. Rec., 131(19): 443-444.

16. Sandoval, E., Morales, G., Ybarra, N., Barrios, M. and Borges, J. (2011) Comparison between two different models of McMaster cameras used for coproscopic counting in the diagnosis of gastroenteric nematode infections in ruminants. Zoo. Trop., 29(1): 495-501.

17. Pinilla, J.C. and Da Silva, N. (2019) Infection dynamics of Cystoisospora suis (Isospora suis) on a pilot swine farm in Carabobo State, Venezuela. Rev. Mex. Cien. Pec., 10(1):149-160.

18. IBM. (2012) SPSS Statistics for Windows, Version 21.0. IBM Corporation, Armonk, NY.

19. Schubnell, F., von Ah, S., Graage, R., Sydler, T., Sidler, X., Hadorn, D. and Basso, W. (2016) Occurrence, clinical involvement and zoonotic potential of endoparasites infecting Swiss pigs. Parasitol. Int., 65(6 Pt A): 618-624.

20. Estevez, G.E. and Levine, J.A. (1985) Examination of preserved stool specimens for parasites: Lack of value of the direct wet mount. J. Clin. Microbiol., 22(4): 666-667.

21. Dryden, M.W., Payne, P.A., Ridley, R. and Smith, V. (2005) Comparison of common fecal flotation techniques for the recovery of parasite eggs and oocysts. Vet. Ther., 6(1): $15-28$.

22. Truant, A.L., Elliott, S.H., Kelly, M.T. and Smith, J.H. (1981) Comparison of formalin-ethyl ether sedimentation, formalin-ethyl acetate sedimentation, and zinc sulfate flotation techniques for detection of intestinal parasites. J. Clin. Microbiol., 13(5): 882-884.

23. Cringoli, G., Rinaldi, L., Veneziano, V., Capelli, G. and Scala, A. (2004) The influence of flotation solution, sample dilution and the choice of McMaster slide area (volume) on the reliability of the McMaster technique in estimating the faecal egg counts of gastrointestinal strongyles and Dicrocoelium dendriticum in sheep. Vet. Parasitol., 123(1-2): 121-131.

24. Roepstorff, A. and Nansen, P. (1998) Epidemiology, Diagnosis and Control of Helminth Parasites of Swine. FAO Animal Health Manual, Rome.

25. Vadlejch, J., Petrtýl, M., Zaichenko, I., Čadková, Z., Jankovská, I., Langrová, I. and Moravec, M. (2011) Which McMaster egg counting technique is the most reliable? Parasitol. Res., 109(5): 1387-1394.

26. Dib, L.V., Palmer, J.P., de Lima, C.D., Ferreira, R.C., Pereira, O.M., Antunes, C.M., Reis, M.R., Monteiro, A.B., Machado, A.C. and da Silva, A. (2019) Comparison of four parasitological techniques for laboratory diagnosis of eggs from Spirometra spp. in wild mammal fecal samples. Acta. Parasitol., 64(4): 942-949. 